Ma Lidong \& Sven Tarp **

\title{
Galileo and the Enigma of -ic/-ical Adjectives: New Techniques to Meet Old Challenges
}

\begin{abstract}
One of the challenges that non-native speakers are facing when writing in English is the use of the suffixes -ic and -ical in connection with a big number of adjectives. L2 learners, even at a high proficiency level, sometimes have doubts about the form they should use in a concrete context. Other times they are simply not aware that they have a problem. The article will look at the assistance they can get in traditional dictionaries as well as some of the new digital writing assistants. It will analyze and classify adjectives ending in -ic and -ical and try to detect some trends that may be relevant for learners at different levels. It will then propose a multidimensional solution that can be incorporated into a digital writing assistant. The proposal includes various types of assistance, even to writers who are not aware of any problem. It also has a pedagogical dimension that makes it particularly relevant to non-native learners of English.
\end{abstract}

\section{Keywords}

linguistic morphology; lexicography; -ic/-ical adjectives; classification criteria; lexical knowledge; L2 writing; dictionaries; writing assistants; disruptive technologies; contextualization

\section{Introduction "from a new angle"}

Around 1590, the Italian mathematician Galileo Galilei dropped two spheres of different masses from the Leaning Tower in Pisa, as reported by one of his disciples (Viviani 1717: 602). He thereby proved that bodies fall at the same speed independently of their weight, thus refuting the Aristotelian natural philosophy of the day. This was just one of several scientific contributions by this Italian genius, who forty years later was accused of heresy by the Inquisition after repeatedly claiming that the Sun, and not the Earth, was the centre of the known universe. To save his life, he admitted that he was mistaken. But according to the legend, he proudly whispered the classic words "eppur si muove" with reference to our planet's movement around the Sun. This was another heavy blow to the Aristotelian cosmology that shortly after ran out of arguments.

More than three centuries later, when discussing Galileo's outstanding contributions, Einstein/ Infeld (1938: 92) observed that the "real advances in science" are marked by the ability, not only to raise new questions and possibilities, but also "to regard old questions from a new angle".

We consider this last observation to have big relevance for the times in which we live. Recent years have been marked by the so-called Fourth Industrial Revolution and its incredible technological breakthroughs that are disrupting almost every industry in every country and changing our daily life in so many ways. According to Schwab (2015), who coined the term, we can expect much more from this Revolution in the years to come:

1 "And yet it moves."

\footnotetext{
*Ma Lidong

Centre for Lexicographical Studies

Guangdong University of Foreign Studies

E-mail:mark2587@126.com
}

Sven Tarp

Centre for Lexicography

Aarhus University

E-mail:st@cc.au.dk 
The possibilities of billions of people connected by mobile devices, with unprecedented processing power, storage capacity, and access to knowledge, are unlimited.

Lexicography, as a millennial cultural practice, has not escaped the tentacles of technological disruption. During the past decades, dictionaries have migrated from the printed book format - via handheld devices, CD-ROMs, and DVDs - to downloadable applications and online information portals; (see, e.g., Rundell 2014, Winestock/Jeong 2014, Fuertes-Olivera 2016, and Fuertes-Olivera et al. 2018). The Cambrian explosion seems to continue. Lexicographers have now started using artificial intelligence in their work. This heralds completely new products such as intelligent dictionaries that adapt to their users' needs in each concrete context. Another innovation that has been underway for some time is the integration of the lexicographical product into various types of software and services that are placed at the high end of the value chain. Simonsen (2017) and Fuertes-Olivera (2019), among others, expect this integration to create the technological conditions for a new business model that can replace the current obsolete one and bring economic prosperity back to the producers of high-quality lexicographical data. Only the future will know.

One of the new integrated products is the digital writing assistant. Various scholars have approached this kind of software from different angles during the past decade, among them Verlinde (2011), Paquot (2012), Wanner et al. (2013), Granger/Paquot (2015), Tarp et al. (2017), Lew et al. (2018), Frankenberg-García et al. (2019), Tarp (2019, 2020), and Frankenberg-García (2020). A number of writing assistants have already been launched in various languages. Apart from Microsoft's Spelling and Grammar Checker, which most people know, we can here mention Academic Writing Assistant, Ginger, Grammarly, ProWritingAid, WhiteSmoke, Write Assistant, and Writefull. These tools vary considerably in functionality and quality, but all of them attempt, in one way or another, to assist their users when writing in either their native language or a foreign language.

Writing assistants like the ones mentioned are driven by language models that have been trained on big corpora. They also rely on lexicographical databases to one extent or another. The most advanced assistants are integrated into the programs people typically use when they write while others require the artisanal method of copy and paste. All of them are designed to "observe" their users. The letters, words, and expressions typed by the latter are always placed in a context. The language model can then analyze the context and, if necessary, provide suggestions and corrections adapted to this context. Some of the tools also allow their users to consult the lexicographical database in case of doubt. This takes us back to the above observation by Einstein/Infeld (1938).

A classic challenge for non-native learners of English is the use of the suffixes -ic and -ical in connection with a relatively big number of English adjectives. This holds true even for learners at an advanced proficiency level, among them those who aspire to practice academic writing. In this section, we have already used the spelling forms academic, classic, economic, lexicographical, scientific, and technological, but not the forms academical, classical, economical, lexicographic, scientifical, and technologic, which can also be found in real texts. Are we right? What is the logic behind this? Is there any rule that may help us? When we consult some of the many webbased language fora, we may get recommendations for specific pairs of -ic/-ical adjectives, for instance, that we should avoid specifical. But we are also told that there is no general rule to guide us. In case of doubt, we are referred to dictionaries for more information. But do these reference tools actually provide the required assistance? And what about the collateral consequences? Any consultation of an external resource is, by definition, a time robber that takes focus away from the content of the writing process. What happens if we are not even aware that we have a problem?

Disruptive technologies now invite us to regard this old question "from a new angle", from the angle of writing assistants. But we should not only look at these tools as they are currently designed. It is even more important to consider what they could develop into with constructive input from lexicographers, lexicologists, and other relevant experts. The choice between -ic and -ical may be seen as a small problem, but there are many similar challenges waiting for new 
technological eyes and angles, both in English and other languages. This article should therefore be viewed as a case study that may inspire a similar approach to other "old questions".

In the following, we will first look at some of the challenges which-ic/-ical adjectives pose to non-native learners as well as the assistance they can get in traditional dictionaries and some of the new writing assistants. The -ic/-ical adjective pairs will be analyzed and classified and we will try to detect some trends that may be relevant for learners at different levels. Based on this, we will make a proposal for a multidimensional treatment of -ic/-ical adjectives in an integrated writing assistant. The proposal will include assistance to writers who are not aware that they have problems. The new technologies have made this possible.

\section{The challenge}

The derivational suffixes -ic and -ical are highly productive in the English language. They contribute to the understanding of English word formation, but sometimes they may also create problems and doubts when non-native speakers have to choose between the two suffixes. The total number of -ic/-ical words and word pairs amounts to several thousand. A Google search presented in The Oxford Handbook of Derivational Morphology "yielded 11,966 unique stems that take -ic, -ical, or both suffixes" (Aronoff/Lindsay 2014: 81). Of these, 10,613 favoured the -ic form and 1,353 the -ical form. This is a considerable number of words. To get a picture of the most frequent ones, we wrote a simple program and extracted 2,171 -ic words, 560 -ical words, and 152 -ic/ical pairs from a list of adjectives with a minimum of three occurrences in the British National Corpus (see Figure 1). The list was created using the website Phrases in English (Fletcher 2011) that allowed us to check n-gram patterns by designating the part-of-speech tags.

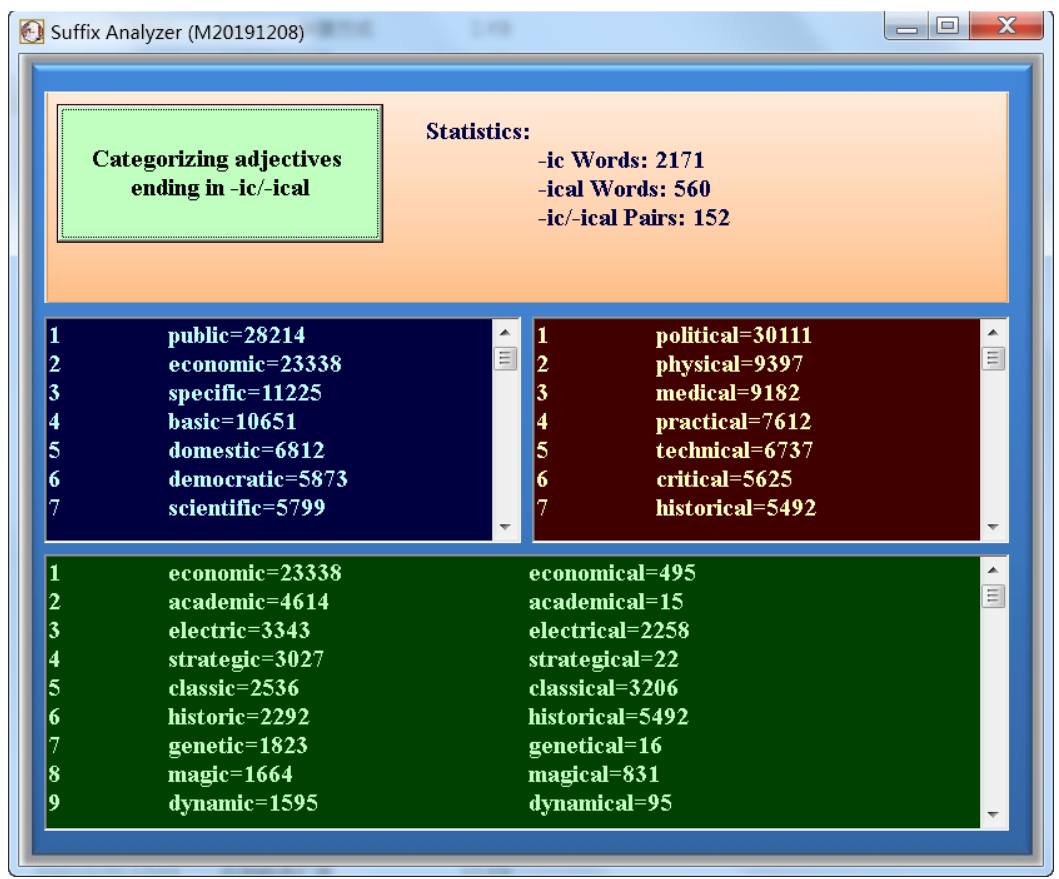

Figure 1: Interface of the extraction program with search results

As the total number of extracted $-i c$ and $-i c a l$ words indicates, there are many more adjective pairs with fewer occurrences that may pose problems for non-native learners who need to use them in written texts. At the other end of the scale, it is noteworthy that some of the extracted adjectives are among the most frequent words in the English language. Table 1 shows a list of -ic 
and -ical words extracted from Longman Communication 3000. This document contains "a list of the 3000 most frequent words in both spoken and written English" which "account for 86\% of the language". As can be seen, there are $29-i c$ and -ical adjectives included in the list. This implies that around one percent of the most frequent English words are adjectives ending in the derivational suffixes -ic or -ical. To this should be added the $11-i c$ and -ical nouns included in the list. Some of these - like music, critic, magic, and statistic - may compete with -ical adjectives as premodifiers in collocations, terms, and other expressions. Music, for instance, is found in frequent collocations and terms like music business, music hall, music industry, music festival, and music teacher.

\begin{tabular}{|c|c|c|c|c|}
\hline FREQUENCY & \multicolumn{2}{|c|}{-IC WORDS } & \multicolumn{2}{|c|}{-ICAL WORDS } \\
\hline $1-1000$ & $\begin{array}{l}\text { basic } \\
\text { economic } \\
\text { music } \\
\text { public } \\
\text { specific }\end{array}$ & $\begin{array}{r}\text { ADJ } \\
\text { ADJ } \\
\mathbf{N} \\
\text { ADJ } \\
\text { ADJ } \\
\end{array}$ & $\begin{array}{l}\text { physical } \\
\text { political }\end{array}$ & $\begin{array}{l}\text { ADJ } \\
\text { ADJ }\end{array}$ \\
\hline $1001-2000$ & $\begin{array}{l}\text { academic } \\
\text { characteristic } \\
\text { democratic } \\
\text { domestic } \\
\text { plastic } \\
\text { public } \\
\text { republic } \\
\text { scientific } \\
\text { topic } \\
\text { traffic }\end{array}$ & $\begin{array}{r}\text { ADJ } \\
\mathbf{N} \\
\text { ADJ } \\
\text { ADJ } \\
\mathrm{N} \\
\mathrm{N} \\
\mathrm{N} \\
\text { ADJ } \\
\mathrm{N} \\
\mathrm{N} \\
\end{array}$ & $\begin{array}{l}\text { critical } \\
\text { historical } \\
\text { medical } \\
\text { practical } \\
\text { technical } \\
\text { typical }\end{array}$ & $\begin{array}{l}\text { ADJ } \\
\text { ADJ } \\
\text { ADJ } \\
\text { ADJ } \\
\text { ADJ } \\
\text { ADJ }\end{array}$ \\
\hline 2001-3000 & $\begin{array}{l}\text { classic } \\
\text { critic } \\
\text { dramatic } \\
\text { electric } \\
\text { electronic } \\
\text { ethnic } \\
\text { magic } \\
\text { organic } \\
\text { statistic } \\
\text { strategic }\end{array}$ & $\begin{array}{r}\text { ADJ } \\
\mathbf{N} \\
\text { ADJ } \\
\text { ADJ } \\
\text { ADJ } \\
\text { ADJ } \\
\mathbf{N} \\
\text { ADJ } \\
\mathrm{N} \\
\text { ADJ }\end{array}$ & $\begin{array}{l}\text { chemical } \\
\text { chemical } \\
\text { classical } \\
\text { musical } \\
\text { psychological } \\
\text { radical } \\
\text { theoretical }\end{array}$ & $\begin{array}{l}\mathbf{N} \\
\text { ADJ } \\
\text { ADJ } \\
\text { ADJ } \\
\text { ADJ } \\
\text { ADJ } \\
\text { ADJ }\end{array}$ \\
\hline
\end{tabular}

Table 1: -ic/-ical words among the 3,000 most frequent English words

Let us take a few examples from the previous section and add the competing morphological variant: 


\begin{tabular}{|l|l|}
\hline \multicolumn{2}{|c|}{-IC/-ICAL OPTIONS IN CONCRETE SENTENCES } \\
\hline $\mathbf{1}$ & This was just one of several scientific/scientifical contributions ... \\
\hline $\mathbf{2}$ & He proudly whispered the classic/classical words ... \\
\hline $\mathbf{3}$ & They also rely on lexicographic/lexicographical databases ... \\
\hline $\mathbf{4}$ & They expect it to create the technologic/technological conditions ... \\
\hline $\mathbf{5}$ & The business model can bring economic/economical prosperity ... \\
\hline $\mathbf{6}$ & Learners who aspire to practice academic/academical writing ... \\
\hline $\mathbf{7}$ & We may get recommendations for specific/specifical pairs of adjectives ... \\
\hline
\end{tabular}

Table 2: Sentences with -ic/-ical adjective pairs

Each of these adjective pairs is a potential source of doubts and mistakes when non-native speakers intend to write English texts. In some cases, the two variants may have different meanings or frequencies, and in other cases, one of them may be the preferred one in specific collocations and terms. In this respect, it does not matter whether one of the two variants is almost non-existing or only has a very low frequency in comparison to its counterpart. How should the learners know? The Internet, which may be useful when handled appropriately, may also add to their confusion. Here, they can find several morphological variants that are not registered in the carefully selected texts that compose the British National Corpus. One such example is specifical that has 742,000 occurrences whereas specific has six thousand times as many occurrences $(4,420,000,000)$. With all right, various web fora discourage writers from using this variant (see Figure 2). But the very fact that specifical can be found 742,000 times on the Internet may confuse some writers. And even more so as it also has been incorporated into various online dictionaries as a lemma, among them prestigious ones like Collins English Dictionary where it is treated as "another word for specific" (see Section 4). Something similar happens to other very low-frequency -ic and -ical variants like domestic and theoretic.

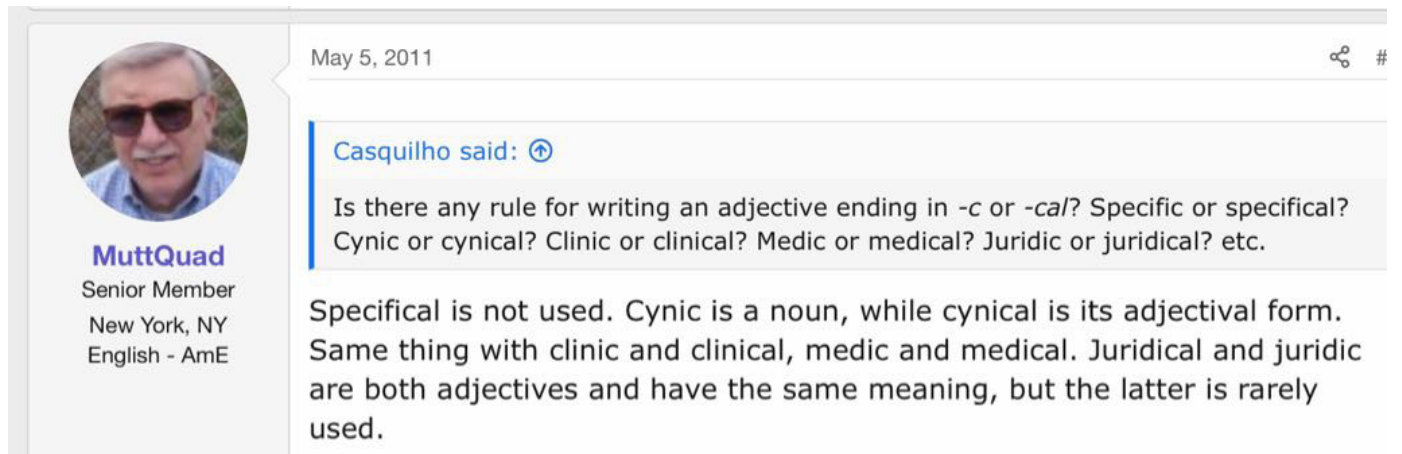

So, there really is no "rule" to the pattern of your examples.

Figure 2: Screenshot from WordReference.com Language Forums

Another example of the challenges posed to learners is the binomial academic writing and academical writing. A general Google search shows 22,900,000 and 3,600 occurrences, respectively. This is a huge and statistically very significant difference. There is therefore little doubt that academic writing is the variant that should be recommended in this case. However, the overwhelming prominence of one morphological variant does not necessarily mean that nonnative learners may find it easy to choose this variant. On the Internet, they can, for instance, access a webpage where the School of Cultural Studies at one of Russia's top universities offers a one-year course in "academical writing" (see Figure 3). They can also read a Mexican article that 
discusses "didactic strategies to improve the competencies in (...) academical writing of future teachers" (Cabral et al. 2018). These two examples show that the -ic/-ical adjective pairs pose a real challenge for non-native speakers of English, even among those who are expected to master academic writing.

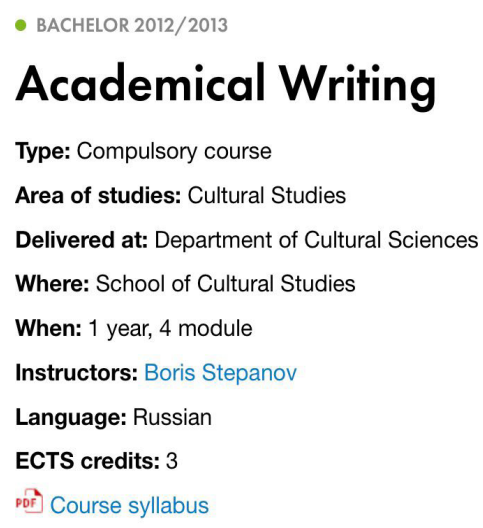

Figure 3: Screenshot with advertisement for Russian course in "academical writing"

To assist non-native learners that have problems with -ic/-ical adjectives, it is first necessary to determine when exactly they need this assistance and whether it can actually be provided. In this respect, it is possible to distinguish between three different situations when the writers have to choose either an -ic or an -ical morphological variant:

1. They know which morphological variant to use.

2. They do not know or have doubts about which variant to use.

3. They are not aware of any potential problem.

In the first situation, no lexicographical assistance is required. But can the writers' knowledge be taken for granted? Are they too confident? If this is the case, they risk making mistakes. In the second situation, assistance is needed to inform the writers about the best choice in each case. This is where traditional dictionaries should provide help although they, as we will see, only do so to a limited extent. These limitations have to be addressed and more holistic solutions developed. However, this does not exclude that some of the concrete solutions found in existing dictionaries may inspire our final proposal. As to the third situation, it has not been possible to provide any assistance until now. But new techniques now allow us to solve at least part of the problem. This solution will be the most innovative part of our proposal. But before it can be developed, we need to classify the -ic/-ical adjective pairs and examine their treatment in dictionaries and other information tools.

\section{Classification of -ic/-ical adjective pairs}

There is no single way of classifying -ic/-ical adjective pairs. As in other disciplines, the elements belonging to a set can be classified in various ways based on different criteria. At a very high level of abstraction, the people living in a specific society, for instance, can be separated into social classes based on their relationship with the means of production. However, the same group of people can also be subdivided and classified according to ethnicity, age, gender, education, job, health, housing, etc. None of these classification criteria are better or worse than the other ones as their relevance in each case depends on the specific purpose of the classification. The same holds true for the -ic/-ical adjective pairs. They can be classified from the point of view of linguistic morphology, but they can also be classified from the perspective of a specific 
lexicographical function like "assistance to L2 writing" (see Tarp 2014). In this section, we will first look at "traditional" morphological classifications and then we will propose a lexicographical classification adapted to the purpose of this article.

Suffixes change the word class, for instance from verb to noun, and from noun to adjective. In some cases, they can also change meaning. Many adjectives can be identified by their suffixes, even though the meanings of the suffixes are determined by the contexts in which they are used. According to Quirk et al. (1985: 1552-1556), typical adjective suffixes can be separated into denominal suffixes and deverbal suffixes that are used to form adjectives from nouns and verbs, respectively. The first category comprises the suffixes -ed, -ful, -ish, -less, -like, -ly, -y; -al (-ial, -ical), -esque, -ic, and -ous (-eous, -ious, -uous), whereas the second category includes the suffixes -able (-ible) and -ive (-sive, -ative). This classification highlights the lexico-grammatical character of the bases to which the suffixes are usually attached.

The denominal suffixes can be further divided into two subcategories. The first one consists of the suffixes -ed, -ful, -ish, -less, -like, -ly, and $-y$, all of which retain a native flavour. The second subcategory comprises the suffixes -al (-ial, -ical), -esque, -ic, and -ous (-ious, -eous) that are of foreign origin and preserve a touch of this origin. As can be seen, this classification from the point of view of linguistic morphology is based on the origin of the suffixes, and variation of the forms has also been taken into consideration. However, linguistic morphology does not treat the derivational suffixes $-i c$ and -ical as a pair, and this may cause confusion. Non-native learners who have some morphological training may know that the suffix -ical is a variant of -al, and that the final $-y$ of the bases - for instance in bibliography, geology, geometry, pedagogy, and philosophy - can be replaced to form adjectives. But this general knowledge scarcely helps them when they have to choose between the competing suffixes -ic and -ical in concrete adjective pairs like bibliographic/bibliographical, geologic/geological, geometric/geometrical, pedagogicl pedagogical, and philosophic/philosophical.

The two suffixes have different etymologies. According to Merriam-Webster Dictionary, -ic has its origin in Latin and entered Modern English via Anglo-French and Middle English, whereas -ical comes directly from Late Latin via Middle English. Other researchers trace them back even longer, to Old Greek and sometimes also Sanskrit. Like other general English dictionaries, Merriam-Webster includes two separate articles for $-i c$ and -ical. The adjective suffix -ic, for instance, comprises eight senses, each of them with very abstract definitions illustrated by an adjective (see Figure 4). 
-ic adjective suffix

1: having the character or form of

: being

//panoramic

: consisting of

//runic

2a: of or relating to

//aldermanic

b: related to, derived from, or containing

//alcoholic

3: in the manner of

: like that of

: characteristic of

//Byronic

4: associated or dealing with

//Vedic

: utilizing

//electronic

5: characterized by: exhibiting

//nostalgic

: affected with

//allergic

6: caused by

//amoebic

7: tending to produce

//analgesic

8: having a valence relatively higher than in

compounds or ions named with an adjective

ending in -ous

//ferric iron

Figure 4: Excerpt from the article "-ic" in Merriam-Webster Dictionary

-ical adjective suffix

:-IC

//symmetrical

//geological

- sometimes differing from -ic in that adjectives

formed with -ical have a wider or more transferred

semantic range than corresponding adjectives in -ic

Figure 5: Excerpt from the article "-ical" in Merriam-Webster Dictionary

Contrary to the -ic entry, the article "-ical" contains only one sense where this suffix is simply defined as "-IC" and illustrated with symmetrical and geological (see Figure 5). But the article also informs that -ical sometimes differs "from -ic in that adjectives formed with -ical have a wider or more transferred semantic range than corresponding adjectives in -ic". This last comment may be correct, but it appears vague and does not contribute much to an easy-to-handle classification of adjectives ending in -ic and -ical. And neither does Merriam-Webster's four definitions of the noun suffix -ic: ": one having the character or nature of: one belonging to or associated with: one exhibiting or affected by: one that produces". 


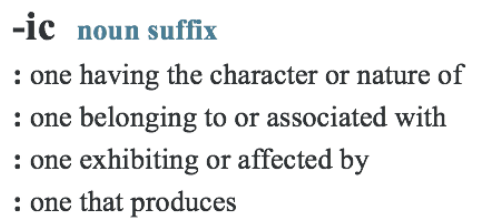

Figure 6: Excerpt from the article "-ic" in Merriam-Webster Dictionary

In this respect, Merriam-Webster is not different from many other dictionaries. Very general and highly abstract definitions of the two suffixes are not particularly useful for an in-depth understanding of adjectives ending in -ic and -ical. Differences between the meanings of one pair of -ic/-ical adjectives cannot be generalized to other pairs, but are unique for each of them (see, e.g., Lindsay/Aronoff 2013: 136).

Another way of classifying the -ic/-ical adjectives is by frequency. This is a common method within linguistic morphology. As mentioned in the previous section, we used a homemade program to extract -ic/-ical words from a list of adjectives that was imported from the British National Corpus via the website Phrases in English. The result was a list of -ic/-ical words that occur at least three times in this Corpus. This minimum frequency threshold was established to ensure that the list includes the relatively low-frequency adjective pairs that learners of English at a high proficiency level may use or encounter. The extracted -ic adjectives are then sorted by frequency. A descending order gives prominence to the most frequent words. The -ic adjectives and their -ical counterparts are listed in contrast with frequency counts for easier observation and comparison. A total of 152 adjective pairs ending in -ic/-ical suffixes were extracted. Table 3 shows the 20 highest ranked pairs followed by the number of occurrences in the British National Corpus.

\begin{tabular}{|c|lr|lr|}
\hline RANK & -IC WORDS & -ICAL WORDS & \\
\hline 1 & economic & 23,338 & economical & 495 \\
\hline 2 & academic & 4,614 & academical & 15 \\
\hline 3 & electric & 3,343 & electrical & 2,258 \\
\hline 4 & strategic & 3,027 & strategical & 22 \\
\hline 5 & classic & 2,536 & classical & 3,206 \\
\hline 6 & historic & 2,292 & historical & 5,492 \\
\hline 7 & genetic & 1,823 & genetical & 16 \\
\hline 8 & magic & 1,664 & magical & 831 \\
\hline 9 & dynamic & 1,595 & dynamical & 95 \\
\hline 10 & symbolic & 1,350 & symbolical & 3 \\
\hline 11 & tragic & 1,202 & tragical & 6 \\
\hline 12 & fantastic & 1,134 & fantastical & 46 \\
\hline 13 & atomic & 1,091 & atomical & 226 \\
\hline 14 & syntactic & 881 & syntactical & 33 \\
\hline 15 & comic & 828 & comical & 132 \\
\hline 16 & problematic & 739 & problematical & 128 \\
\hline 17 & poetic & 717 & poetical & 52 \\
\hline 18 & ironic & 703 & ironical & 88 \\
\hline 19 & graphic & 688 & graphical & 643 \\
\hline 20 & geometric & 586 & geometrical & 191 \\
\hline
\end{tabular}

Table 3. The first 20 pairs of -ic/-ical adjectives

Based on the degree of difference in word frequency, the adjective pairs included in Table 3 can be further divided into three subcategories:

1. A subcategory where both the -ic forms and the -ical forms are prominent for their high frequency (see Table 4).

2. A subcategory where the -ic forms have much higher word frequency than the -ical forms (see Table 5). 
3. A subcategory where both the -ic forms and the -ical forms have relatively lower, but roughly similar frequency (see Table 6).

\begin{tabular}{|c|lr|lr|}
\hline RANK & -IC WORDS & & -ICAL WORDS & \\
\hline 1 & economic & 23,338 & economical & 495 \\
\hline 3 & electric & 3,343 & electrical & 2,258 \\
\hline 5 & classic & 2,536 & classical & 3,206 \\
\hline 6 & historic & 2,292 & historical & 5,492 \\
\hline
\end{tabular}

Table 4. Prominent high-frequency -ic/-ical pairs

\begin{tabular}{|c|lr|lr|}
\hline RANK & -IC WORDS & & -ICAL WORDS & \\
\hline 2 & academic & 4,614 & academical & 15 \\
\hline 4 & strategic & 3,027 & strategical & 22 \\
\hline 7 & genetic & 1,823 & genetical & 16 \\
\hline 9 & dynamic & 1,595 & dynamical & 95 \\
\hline 10 & symbolic & 1,350 & symbolical & 3 \\
\hline 11 & tragic & 1,202 & tragical & 6 \\
\hline 14 & syntactic & 881 & syntactical & 33 \\
\hline
\end{tabular}

Table 5. High-frequency -ic forms with low-frequency -ical counterparts

\begin{tabular}{|c|ll|ll|} 
RANK & -IC WORDS & & -ICAL WORDS & \\
\hline 15 & comic & 828 & comical & 132 \\
\hline 16 & problematic & 739 & problematical & 128 \\
\hline 19 & graphic & 688 & graphical & 643 \\
\hline 20 & geometric & 586 & geometrical & 191 \\
\hline
\end{tabular}

Table 6. -ic/-ical pairs with relatively lower, but roughly similar frequency

The remaining -ic/-ical pairs can be classified in a similar manner. However, the decrease of the frequency of the -ic forms provides instances where there is a clear preference for the -ical counterparts. Immunological, for example, has 107 occurrences whereas immunologic only appears three times (see Table 7).

\begin{tabular}{|c|lc|lr|}
\hline RANK & -IC WORDS & & -ICAL WORDS & \\
\hline 140 & immunologic & 3 & immunological & 107 \\
\hline 147 & pharmacologic & 3 & pharmacological & 65 \\
\hline 148 & physiologic & 3 & physiological & 620 \\
\hline 150 & serologic & 3 & serological & 54 \\
\hline 151 & stereotypic & 3 & stereotypical & 119 \\
\hline
\end{tabular}

Table 7. Sample word pairs in which the -ical suffix is prominent

At these relatively lower frequency levels, we can also identify more -ic/-ical pairs with roughly similar numbers of occurrences as well as specialized terms like metric/metrical and biometricl biometrical (see Table 8). 


\begin{tabular}{|c|lr|lr|}
\hline RANK & -IC WORDS & & -ICAL WORDS & \\
\hline 27 & metric & 384 & metrical & 331 \\
\hline 32 & cyclic & 281 & cyclical & 190 \\
\hline 44 & logistic & 148 & logistical & 94 \\
\hline 64 & hemispheric & 67 & hemispherical & 39 \\
\hline 73 & stoic & 39 & stoical & 28 \\
\hline 75 & paramedic & 37 & paramedical & 35 \\
\hline 126 & biometric & 4 & biometrical & 3 \\
\hline
\end{tabular}

Table 8. More -ic/-ical pairs with relatively lower, but roughly similar frequency

The frequency-based classification may serve as a starting point for addressing the confusing -ic/ical pairs. However, in-depth assessment remains to be done. A complication in this regard is that some $-i c$ items also have the potential to function as nouns (e.g. comic, graphic, paramedic). In the extracted list, they are nevertheless treated as adjectives because they are tagged as such in the British National Corpus.

The previous classifications of -ic/-ical adjectives are undoubtedly a source of inspiration for the lexicographical work that has to be done to improve writing assistants. But they cannot be transferred uncritically to lexicography. For non-native learners that need assistance to choose between -ic and -ical forms, information about their etymology, the corresponding adverb, or whether or not a specific -ic premodifier is an adjective or noun, is totally irrelevant. These phenomena may explain some of the non-native speakers' mistakes and doubts. For instance, the existence of adverbs ending in -ically when only adjectives ending in -ic are used (e.g. domestic and domestically) may create confusion among writers that are not familiar with the English language. But non-native writers do not need lengthy linguistic descriptions of these phenomena. On the contrary, they need clear and short recommendations on how to write in English (see Bergenholtz 2003). Anything else would lead to information overload that takes focus away from the topic or content of the writing process (see Gouws/Tarp 2017). In fact, the only information required is an indication of which -ic or -ical form they can use with the right meaning and without "appearing ridiculous" (Scerba 1995: 342), i.e. without using rare or old-fashioned forms that native speakers may find strange or even incorrect. Another thing would be if some learners get curious during the writing process and want to explore a specific word or linguistic issue. In such cases, they may need information about some of the phenomena mentioned. But then they would have shifted to intentional learning and their specific information need would no longer be directly related to the concrete writing process.

From a lexicographical perspective, the fundamental criterion that determines the classification of -ic/-ical adjective pairs is the relevance criterion (see Bothma/Tarp 2012). This implies that a separate class of adjective pairs only is relevant when it requires a specific lexicographical treatment different from the ones that are given to other classes. It is, for instance, not pertinent to distinguish between high-frequency and low-frequency pairs because they will end up having the same lexicographical treatment if they are similar in all other aspects. (This also holds true for the planning of the compilation process where it is not the absolute frequency of the adjective pair as such, but the frequency of its highest-ranking -ic or -ical form that usually determines the order in which they are dealt with.) Now, the aim of a writing assistant in this connection is to help nonnative writers choose an -ic or -ical word that expresses the desired meaning without being too rare or obsolete. This suggests that we should use a combination of the two variables meaning and frequency to obtain an operational lexicographical classification. Based on this idea, the -ic/-ical adjective pairs can be separated into three classes (see Table 9). 


\begin{tabular}{|l|l|}
\hline & Three classes of $-\boldsymbol{i c}$-ical adjective pairs \\
\hline 1 & The two forms have different meanings \\
\hline 2 & The two forms have the same meaning and very different frequency \\
\hline 3 & The two forms have the same meaning and roughly similar frequency \\
\hline
\end{tabular}

Table 9. Lexicographical classification of -ic/-ical adjective pairs

As can be seen, all three classes require that lexicography provides meaning assistance to writers who do not know or have doubts about the meaning of specific adjective pairs. In addition, the first class requires that writers are informed about the different meanings of the two variants and what exactly separates them. The second class requires that writers are guided to use the more frequent variant to avoid "appearing ridiculous". By contrast, the third class does not call for such guidance although some writers may want to confirm the "free choice" and therefore need the pertinent lexicographical information. But, as we will see in the next section, there may also be some challenges related to the right use of collocations.

\section{Tendencies and countertendencies}

Research into the use of -ic and -ical words has revealed a gradual shift from -ical to -ic forms. Although there are many counterexamples, the general tendency to favour the -ic forms is stronger than the countertendency to opt for the -ical forms (see Kaunisto 2007). Yet, we should be aware that a relatively lower frequency of one of the two forms does not necessarily imply that this form has dropped out of use in English and has become outdated. This applies especially to -ic and -ical forms that differ in sense or part of speech.

Many scholars have studied the semantic differentiations and tendencies in the use of -ic and -ical words. We can here mention Patridge (1957), Marchand (1969), Ross (1998), Kaunisto (1999, 2007), Zhang (1999), Gries (2001, 2003), Li (2002), Xu (2010), Lindsay/Aronoff (2013), and Aronoff/Lindsay (2014). Their findings may help learners of English to raise awareness of the differences, tendencies, and patterns in using the words. The corpus-based analysis conducted by Kaunisto (2007), for instance, reveals that some -ical adjectives are becoming obsolete or oldfashioned due to the competition between the suffixes -ic and -ical. Examples of this tendency are domestical, majestical, organical, rustical, scientifical, and socratical. However, the study also finds exceptions and countertendencies that deserve special attention (e.g. fanatical, hysterical, mechanical). In some cases, the -ic adjective and its -ical counterpart are interchangeable, whereas this is not the case in other pairs.

In the following, we will look at the major tendencies and exceptions. We will start in the world of sciences where the suffixes -ic and -ical are particularly productive in the formation of adjectives. A clear shift of preference can be observed over time. The adjectives derived from denominations of sciences with a relatively long history seem to favour the -ical form (e.g. chemical, logical, mathematical, physical). But from the $19^{\text {th }}$ century and onwards, the -ic form is increasingly preferred over its -ical counterpart (e.g. linguistic, neurolinguistic, phonetic). And in the $20^{\text {th }}$ century, new adjectives ending in -ic by far outnumber those ending in -ical (see Kaunisto 2007).

There are cases where the $-i c$ form is the one used in the respective domain or field of study (e.g. atomic, genetic) even when the -ical form can be found in the British National Corpus. The notable increase in the use of -ic forms is also related to a tendency to favour the shorter form to express new senses. This tendency is expressed with particular clearness in the relative development of the adjective pair economic/economical during the past three centuries. Figure 7 shows how the establishment of economics as a scientific discipline in the late 19th century boosted economic as an adjective denoting something "connected with the economy of a country 
or an area, or with the money that a society or an individual has" (Oxford Advanced Learner's Dictionary).

\section{Google Books Ngram Viewer

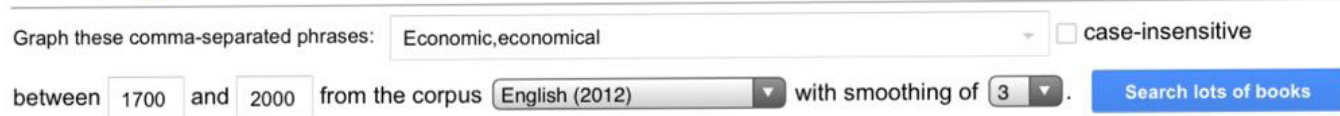

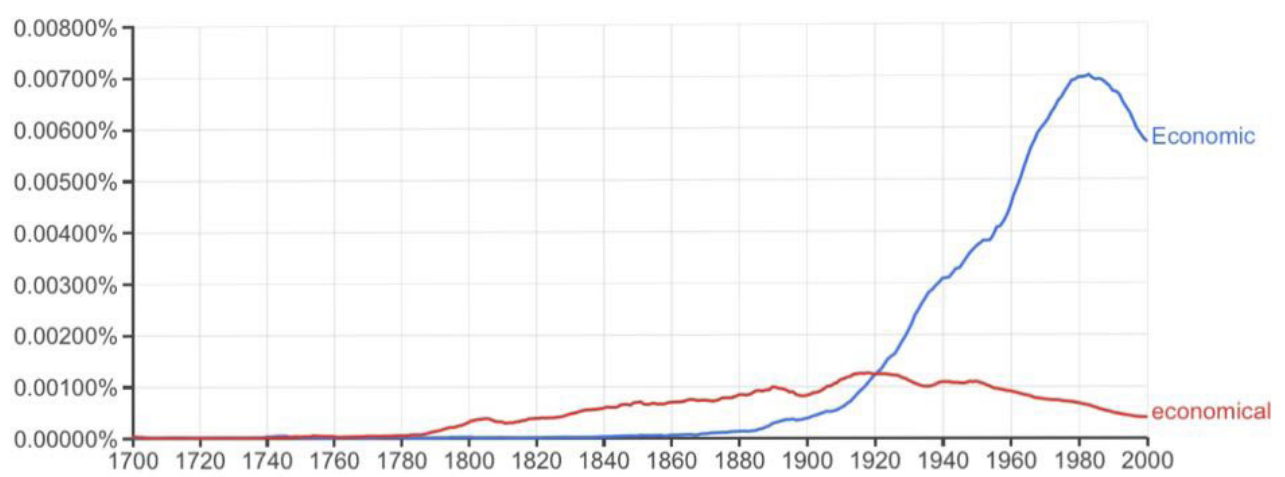

Figure 7: The relative development of economic/economical from 1700 to 2000

Within literary genres, there are several -icl-ical pairs where the -ical form has become rare or obsolete (e.g. comic/comical, dramatic/dramatical, epic/epical, poetic/poetical, prosaicl prosaical, tragic/tragical). By contrast, in the competition between satiric and satirical, it is now the longer form satirical that is the most frequent one. The adjective pairs farcic/farcical and tyrannic/tyrannical are also examples where the -ical form is preferred over its -ic counterpart.

The -ic/-ical word pairs are not limited to adjective pairs. As mentioned above, there are several noun-adjective pairs where the shorter -ic form also has a nominal function. The dominant tendency in these cases is that the -ical form is preferred over the -ic form as an adjective (e.g. logic/logical, rhetoric/rhetorical). But there are also some noun-adjective pairs like magic/magical and comic/ comical where the adjectival function is not exclusively reserved to the-ical form. There are even cases where the -ic forms have prevailed although this form also has a nominal function (e.g. academic, domestic, epidemic, rustic). And finally, there are a few cases like periodic/periodical where the longer -ical form (periodical), rather than the shorter form periodic, denotes a noun.

Some -ic/-ical word pairs also have a corresponding noun ending in -ics denoting a scientific field, theory, or method of action (Marchand 1969: 241). Mechanic/mechanical, mathematicl mathematical, and tactic/tactical are examples of this. The preference for the use of the -ical forms seems to have been established at a relatively early stage. However, the opposite tendency can also be observed. Evidence from historical corpora indicates that the competition between adjective pairs like philosophic/philosophical and theoretic/theoretical eventually led to the dominance of the longer -ical form over the shorter -ic form (Kaunisto 2007). This happened even though the corresponding nouns of these words neither end in -ics nor in -ic. 


\begin{tabular}{|lr|lr|}
\hline ELECTRIC + NOUN & & ELECTRICAL + NOUN & \\
\hline electric field & 171 & electrical engineering & 106 \\
\hline electric shock & 101 & electrical equipment & 105 \\
\hline electric light & 92 & electrical goods & 88 \\
\hline electric fire & 84 & electrical activity & 81 \\
\hline electric power & 60 & electrical appliances & 59 \\
\hline electric guitar & 56 & electrical engineer & 44 \\
\hline electric charge & 46 & electrical engineers & 43 \\
\hline electric current & 42 & electrical power & 39 \\
\hline electric motor & 42 & electrical conductivity & 33 \\
\hline electric shocks & 40 & electrical energy & 32 \\
\hline electric windows & 36 & electrical impulses & 30 \\
\hline electric drill & 35 & electrical fault & 29 \\
\hline electric kettle & 31 & electrical signals & 27 \\
\hline electric car & 29 & electrical signal & 26 \\
\hline electric cars & 29 & electrical stimulation & 26 \\
\hline electric cooker & 28 & electrical union & 26 \\
\hline electric blanket & 27 & electrical circuit & 25 \\
\hline
\end{tabular}

Table 10: Collocations with electric and electrical in the British National Corpus

Finally, there are cases where the choice between the -ic/-ical forms, to a certain degree, depends on the collocates. The adjective pair electric/electrical can illustrate this. Table 10 shows the most frequent collocations with these two adjectives in the British National Corpus. According to Oxford Advanced Learner's Dictionary, the -ic form electric is typically used in connection with words of a greater specificity to describe something that uses or produces electricity (e.g. car, guitar, light), whereas electrical modifies more general nouns (e.g. appliances, engineering, equipment). But the distinction is not always so clear now, and both electric shock and electrical shock can be used.

\section{Treatment in existing dictionaries}

Seemingly in a state of mind oscillating between frustration and fascination, Kaunisto (1999: 343) observes:

\footnotetext{
"A lexicologist embarking on the study of adjective pairs ending in -ic and -ical will find the task riddled with complexities. There simply do not seem to be any clear rules concerning the application of the suffixes. Considering first the adjectives ending in -ic and -ical generally, suffixation appears at first sight to have been applied almost at random, as there are adjectives for which only the -ic variant exists, e.g. basic, dramatic, energetic, on the one hand, and adjectives only ending in -ical, on the other, e.g. medical, typical, and zoological. Additionally, there are some nouns ending in -ic and -ical, based on the corresponding adjectives, which makes the whole array of -ic and -ical words seem even more unsystematically formed."
}

Complex, ruleless, random, and unsystematic. This is the challenge that lexicology has passed on to lexicography. Besides part of speech and frequency, "the degree to which -ic/-ical adjectives in general or some particular -ic/-ical adjectives are semantically similar or even synonymous" (Gries 2003: 46) deserves special attention. From a study of the word pairs historic/historical and electric/electrical, Lindsay/Aronoff (2013: 146) conclude that "the difference between the -ic and -ical forms cannot be generalized across these words" inasmuch as "the meanings are specific to the words themselves". Hence, the words in these "doublets must be individually stored in the lexicon".

The main purpose of a learner's dictionary is precisely to facilitate this individual storage by providing lexicographical assistance to incidental or intentional learning. Such assistance should not only be semantic, but also grammatical. This takes us back to Henry Sweet, the "father" of 
English pedagogical lexicography, who dreamed of "a full reference-grammar" in the form of a dictionary:

\begin{abstract}
"A thoroughly useful dictionary ought, besides, to give information on various grammatical details, which, though they fall under general rules of grammar, are too numerous or too arbitrary and complicated to be treated of in detail in any but a full reference-grammar: such a dictionary ought to give full information about those grammatical constructions which characterize individual words, and cannot be deduced with certainty and ease from a simple grammatical rule." (Sweet 1899: 139).
\end{abstract}

This statement is especially relevant in the case of -ic/-ical adjective pairs, where no general rules without relevant exceptions have been formulated. Non-native speakers who do not know which -ic or -ical variant to choose in a concrete writing situation are typically referred to dictionaries. It therefore seems logical to examine how dictionaries deal with this challenge. Do they provide the required assistance? Do they miss something? Are the lexicographical data clear and unambiguous? To answer these questions, we have examined how the online versions of Collins English Dictionary, Longman Dictionary of Contemporary English, Macmillan Dictionary, Merriam-Webster Dictionary, and Oxford Advanced Learner's Dictionary treat a number of adjective pairs belonging to the three classes defined in Table 9.

\title{
5.1. Adjective pairs with different meanings
}

Some of the 20 most frequent adjective pairs listed in Table 3 have clearly different meanings, among them: economic/economical, classic/classical, historic/historical, and graphic/graphical. It is no surprise that the five dictionaries mentioned have lemmatized both forms of these very frequent -ic/-ical pairs. However, the lexicographical treatment given to them has some interesting nuances. Merriam-Webster, for instance, only compares the usage of the two forms in the article historical, but not in the one concerning historic:

\footnotetext{
"Historic and historical have been used interchangeably by many writers, even in recent years. If you would like to avoid being corrected, however, use historical for matters relating to history (the historical society), and historic to refer to things having great and lasting importance (a historic occasion)."
}

Collins only offers one short usage note attached to historic, but leaves historical and the other adjective pairs without any notes:

"A distinction is usually made between historic (important, significant) and historical (pertaining to history): a historic decision; a historical perspective."

By contrast, Longman does not attach comparative notes to any of the adjective pairs although it provides a short warning under economic:

"Do not confuse with economical (= cheap or not wasteful)."

Macmillan also appears surprisingly reluctant to give usage notes, but the lonely one addressed to economical compensates to some extent for this omission (see Figure 8). This way of designing the usage note seems particularly relevant to users who need assistance to write in English. 


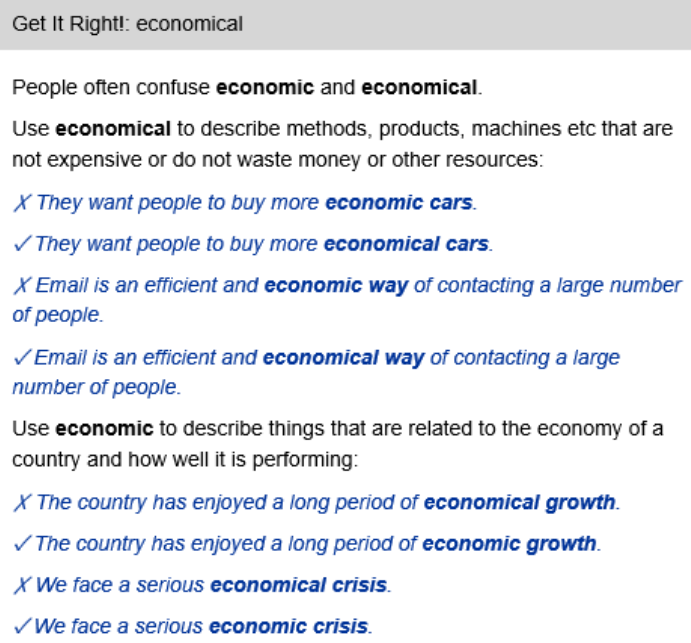

Figure 8: Screenshot with comparative usage note from Macmillam

Different from the four other online dictionaries, Oxford (which is the only declared learner's dictionary) appears much more generous when it comes to usage notes to -ic/-ical adjective pairs. Except for graphic/graphical, there are usage notes to the other four pairs examined. Figure 9 shows the one addressed to classic. For some unaccountable reason, it is not repeated under classical. However, the other adjective pairs have an identical note under both-ic/-ical forms, thus economizing the lexicographer's time.

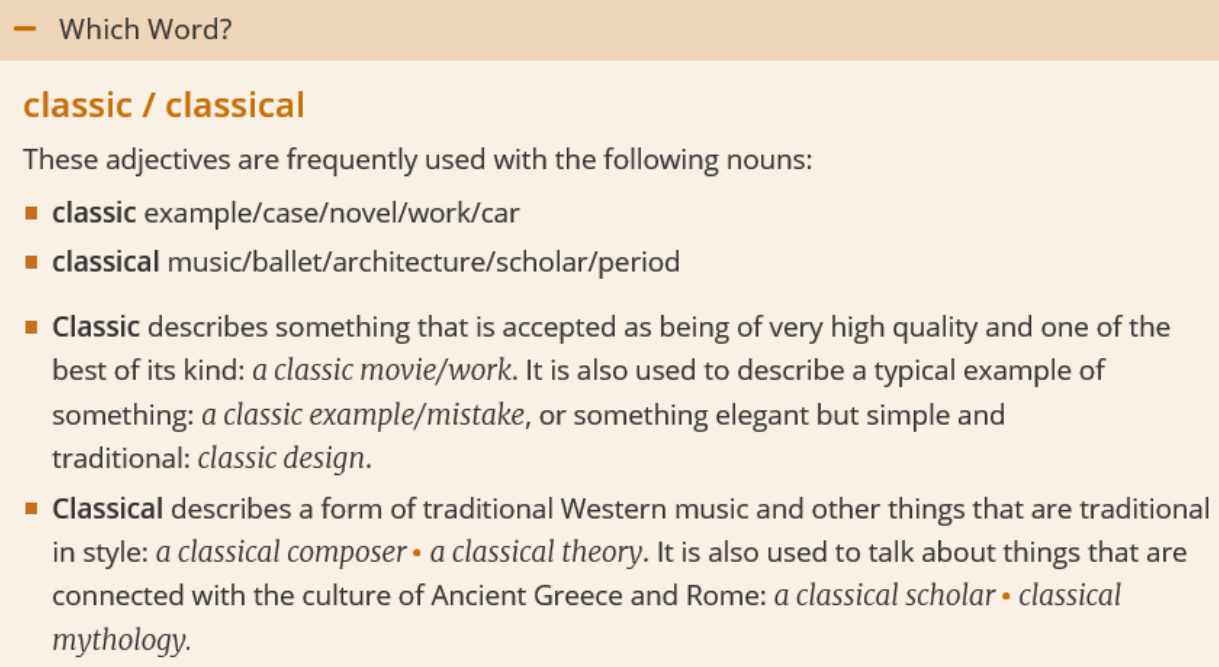

- Classical describes a form of traditional Western music and other things that are traditional in style: a classical composer - a classical theory. It is also used to talk about things that are connected with the culture of Ancient Greece and Rome: a classical scholar • classical mythology.

Figure 9: Screenshot with comparative usage note from Oxford

Among the five dictionaries analyzed above, Oxford is by far the one with the most systematic treatment of -ic/-ical adjective pairs. This systematicity, however, does not extend to the whole dictionary. Other less frequent adjective pairs like comic/comical, magic/magical, and politicl political are not honored with usage notes although such notes can be found in manuals like the Bloomsbury Good Word Guide (Manser 2003). Moreover, there are other pairs ending in -ic and -ical where minor or subtle semantic differences exist (e.g. diabolic/diabolical, fantasticl 
fantastical, opticloptical). Such adjectives also need to be addressed so learners who want to write in English can be guided appropriately.

A comparison of the usage notes from the different dictionaries shows how some of them tend to be very descriptive whereas others, especially the one from Macmillan, are more instructive in terms of practical advice to writing. This fine line between linguistic description and lexicographical instruction is probably due to the fact that all five dictionaries are multifunctional. The lexicographical data are therefore designed to simultaneously assist reading, writing, and intentional learning (see Tarp 2008, and Fuertes-Olivera/Tarp 2014). This broad approach will almost unavoidably lead to data overload in some consultations and data underload in other consultations. The most likely result is a not entirely satisfied user group. Twenty years into the $21^{\text {st }}$ century, the publishing houses behind the five prestigious dictionaries have not yet made full use of the new technologies to differentiate and adapt their products to each of the three functions mentioned, i.e. to create usage-oriented monofunctional tools as demanded by Bergenholtz/ Bergenholtz (2011), among others.

\subsection{Adjective pairs with the same meaning, but different frequency}

There are many cases where the two morphological forms in an -ic/-ical pair have very different frequencies although they may express the same meaning. The reason could be that the less frequent variant is obsolete, old-fashioned, rare, or simply not used by native speakers. But then again: how should non-native learners know? Basical, for instance, is not used by native speakers, but it can nonetheless be found in academic papers by non-native speakers. Ergo there is a problem. We have therefore analyzed how the five dictionaries treat the adjective pairs academicl academical, atomic/atomical, basic/basical, problematic/problematical, specific/specifical, and strategic/strategical. In all these cases, the -ical form is by far the less frequent one. The -ic forms are all high-frequency adjectives and all five dictionaries have, as it could be expected, lemmatized them with the pertinent lexicographical data. However, except for a note attached to problematic in Oxford ("also less frequent problematical"), no mention whatsoever is made of the -ical counterparts in any of these -ic articles. The -ical forms, on the other hand, are treated very differently from dictionary to dictionary, from form to form (see Table 11). Problematical and strategical, for instance, are treated in four of the five dictionaries whereas basical is completely ignored. Longman and Macmillan only deal with a single -ical form each whereas Collins honours five out of six. 


\begin{tabular}{|c|c|c|c|c|c|}
\hline -ICAL FORM & WeBster & Collins & LONGMAN & MaCMILLAN & OXFORD \\
\hline academical & $\begin{array}{l}>\text { goes directly } \\
\text { to academic }\end{array}$ & $\begin{array}{l}\text { "another name for } \\
\text { academic" } \\
>\text { link to academic }\end{array}$ & - & - & - \\
\hline atomical & - & $\begin{array}{l}\text { "a variant form for } \\
\text { atomic (sense } 3 \text { )" } \\
>\text { link to atomic }\end{array}$ & - & - & - \\
\hline basical & - & - & - & - & - \\
\hline problematical & $\begin{array}{l}>\text { goes directly } \\
\text { to problematic }\end{array}$ & $\begin{array}{l}\text { "Problematical } \\
\text { means the same as } \\
\text { problematic" } \\
>\text { link to } \\
\text { problematic }\end{array}$ & - & $\begin{array}{l}>\text { goes directly to } \\
\text { problematic }\end{array}$ & $\begin{array}{l}>\text { goes directly } \\
\text { to problematic }\end{array}$ \\
\hline specifical & $\begin{array}{l}\text { "archaic" } \\
>\text { link to } \\
\text { specific }\end{array}$ & $\begin{array}{l}\text { "another word for } \\
\text { specific" } \\
\text { > link to spcific }\end{array}$ & - & - & - \\
\hline strategical & $\begin{array}{l}>\text { goes directly } \\
\text { to strategic }\end{array}$ & $\begin{array}{l}>\text { goes directly to } \\
\text { strategic }\end{array}$ & $\begin{array}{l}>\text { goes } \\
\text { directly to } \\
\text { strategic }\end{array}$ & - & $\begin{array}{l}>\text { goes directly } \\
\text { to strategic }\end{array}$ \\
\hline
\end{tabular}

Table 11: Lexicographical treatment of low-frequency -ical forms

Dictionary users who do not get any answer when typing one of the -ical adjectives may either think that this adjective does not exist or that they have hit another lemma lacuna. If they do not know the corresponding -ic form, they may get lost in the forest. In any case, they have not got the assistance they deserved and looked for. By contrast, if they hit one of the -ical forms from where they are automatically referred to its -ic form, they are at the least still on the rails. But even so, they may feel confused if they are not told why they were referred to this specific -ic form. Such confusion may prolong the consultation time and have a de-focusing effect on the writing process. Therefore, they ought to be informed explicitly that they have been referred from the -ical form of " $\mathrm{X}$ " to its synonymous -ic form, that the -ical form is not recommended (because the word is obsolete, old-fashioned, rare, or simply not used), and that they should use the -ic form instead. This kind of information could easily be systematized in three or four standard formulations without posing a noticeable burden on the lexicographers.

In Table 11, there are five examples where the low-frequency -ical form is selected and briefly treated in a separate dictionary article. However, only Webster justifies in the article specifical (by adding "archaic") why the users are referred to the -ic form specific. This is very helpful although it could be done even more explicitly. On the contrary, none of the four examples from Collins provides any convincing argument why the users are directed to the -ic forms. In fact, the small notes (e.g. "another name for academic") may lead the users to assume that the -ical forms are just as good as the -ic forms. Figure 10 illustrates the problem. Although specific is listed just below specifical with a total of six senses, there is no indication whatsoever that specifical should not be used. 


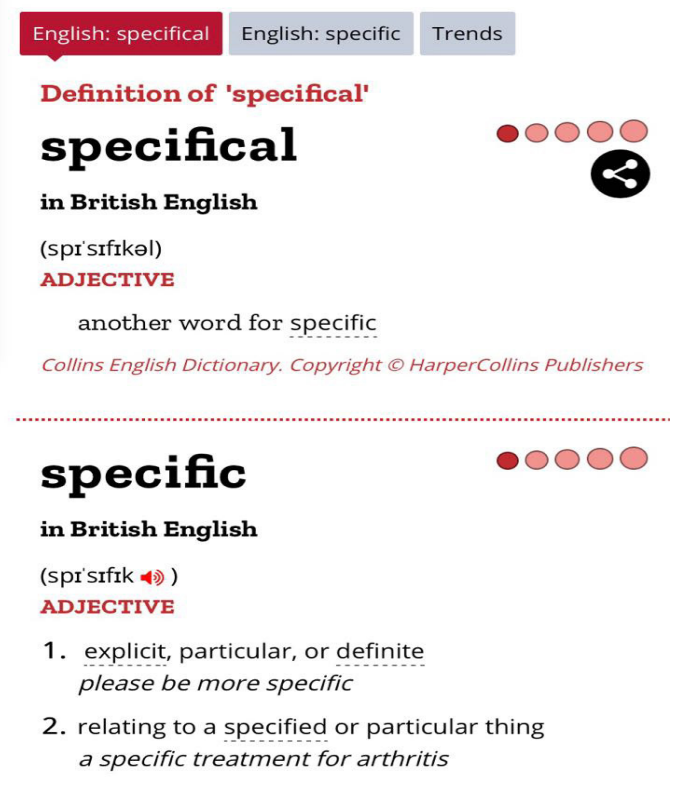

Figure 10: Screenshot from the online Collins English Dictionary

The approach in Collins is extremely descriptive and of little help to non-native speakers who look for assistance to L2 writing. Some dictionaries indicate the most frequent words in the corpus. But what relevance does this indication have if the writers need a not-so-frequent adjective to express a specific meaning? In any case, a general frequency indication is still a piece of implicit information that the users have to interpret correctly. Basically, it is not enough for lexicographers to communicate implicitly with their users. Instead, explicit recommendations should be given in case of possible doubts, as suggested by Bergenholtz (2003).

As to the form basical, none of the dictionaries has selected it, probably due to its low or even zero frequency in the corpora. However, for non-native learners who need assistance to L2 writing, it would make sense to include basical with the following standard text segments: "This word is not used. Use basic instead". As we will see in Section 6, such small standardized text segments may be extremely useful in digital writing assistants.

\subsection{Adjective pairs with the same meaning and similar frequency}

In principle, when two -ic/-ical variants have the same meaning and a roughly similar frequency, there is no reason - except for space restrictions in paper dictionaries - to recommend one or the other as both can be used. However, as shown in Table 10, some of these variants like electricl electrical may have collocational preferences. Others do not show such preferences (e.g. ironicl ironical). We have therefore examined how these two -ic/-ical pairs are handled in the five dictionaries.

None of the five dictionaries treats ironical in a separate article. Instead, the users are directly linked to ironic, where they are informed that ironical is a synonym to ironic, sometimes (in Collins and $O x f o r d$ ) with the additional information that ironical is less frequent. This approach is enough to guide users to write correct English although some users may wonder whether the use of ironical is also adequate. This last kind of user need belongs to the borderland between incidental and intentional learning. It is therefore not needed in a dictionary designed to assist L2 writing but, if required, it could very easily be satisfied with a few words that could be standardized and applied to the relevant -ic/-ical pairs. 
As to adjective pairs electric/electrical, Collins does not lemmatize electrical and takes the users directly to electric where they are informed that the two variants are synonyms. This is not wrong, but it does not help the users to choose the right collocations. The other four dictionaries do lemmatize electrical. Three of them - Longman, Macmillan, and Oxford-also attach comparative notes to electric (but not to electrical) where they explain the differences in terms of usage and collocational preferences. As can be seen in Figure 11, such information may be very relevant to non-native learners.

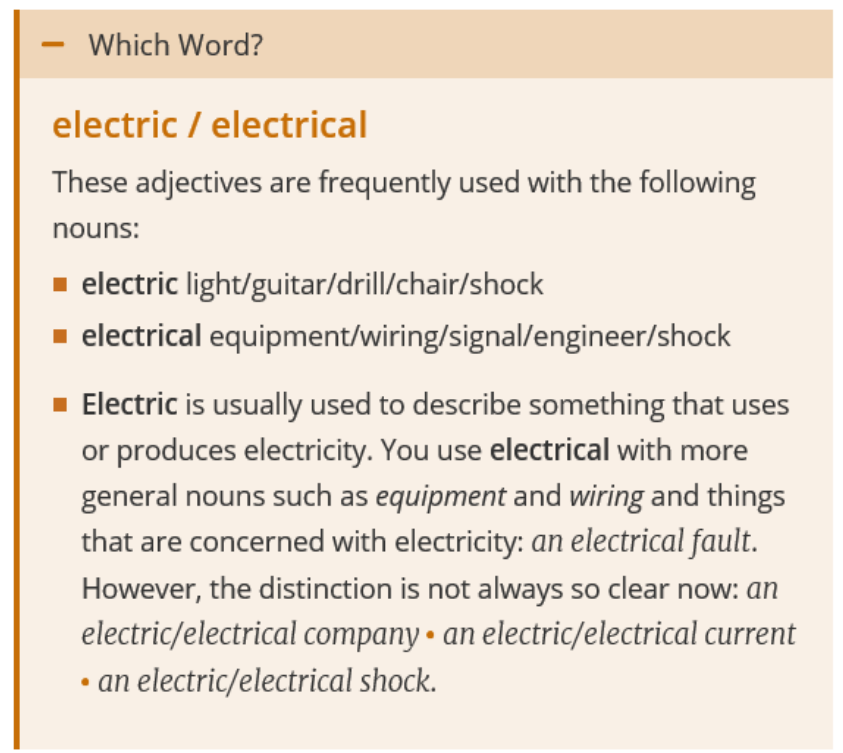

Figure 11: Screenshot with comparative usage note from Oxford

\subsection{Summary}

As mentioned above, a structural problem in all five dictionaries is that they are designed as multifunctional dictionaries. This design is an unfortunate inheritance from the printed dictionary. It implies that the lexicographical data has been prepared to simultaneously assist reading, writing, and intentional vocabulary and grammar acquisition. Users of these dictionaries therefore have to navigate between description and instruction. But as we have also indicated, a few standardized notes could be prepared and added without much extra work for the lexicographers. In the next sections, we will see how such notes would be particularly relevant for digital writing assistants that import part of their data from lexicographical databases.

\section{Treatment in writing assistants}

To conduct a small test of four different writing assistants, we have first taken the full sentences containing the examples listed in Table 2 and applied the -ic/-ical variants that were not used in our text. To this, we have added three sentences that include collocations with electric and electrical as well as one sentence where there is a possible choice between ironic and ironical. In all cases, we have applied the most unlikely variant. We have then tested how Microsoft's Spelling and Grammar Checker, as well as Grammarly and ProWritingAid (the free versions) handle the complete text. Finally, we have rewritten the whole text with Write Assistant activated. Figure 12 shows the results after the text has been copied into Grammarly. 
- This was just one of several scientifical contributions by this Italian genius.

- He proudly whispered the classical words "eppur si muove" with reference to our planet's movement around the Sun.

- Writing assistants also rely on lexicographic databases to one extent or another.

- They expect this integration to create the technologic conditions for a new business model that can replace the current obsolete one and bring economical prosperity back to the producers of high-quality lexicographic data.

- This holds true even for learners at an advanced proficiency level, among them those who aspire to practice academical writing.

- When we consult some of the many web-based language fora, we may get recommendations for specifical adjectives.

- Jimi Hendrix took the stage at the Woodstock music festival and played a fantastic version of "The Star Spangled Banner" on his electrical guitar.

- This article is about the evolution of electric equipment from its early history until today.

- An electrical shock occurs when a person comes into contact with an electric energy source.

- It is ironical that Sherlock Holmes, who was methodical in high complexity thinking like deductive reasoning, was highly disorganized in his personal life.

Figure 12: Screenshot from Grammarly indicating possible problems

As can be seen in Figure 12, Grammarly has alternative suggestions to five of the 13 adjectives in italics. In this respect, the software performs a little better than Microsoft's Spelling and Grammar Checker and ProWritingAid that only offer four and two alternative solutions, respectively (see Table 12). 


\begin{tabular}{|c|c|c|c|c|}
\hline -IC/-ICAL FORM & Microsoft & GRAMMARLY & ProWritingAid & Write Assistant \\
\hline scientifical & $>$ scientifically & - & - & $\begin{array}{l}>\text { scientific } \\
\text { scientifically }\end{array}$ \\
\hline classical & - & - & - & $\begin{array}{l}>\text { classic } \\
\text { classical }\end{array}$ \\
\hline lexicographic & - & - & - & $\begin{array}{c}>\text { lexicographical } \\
\text { lexicographic }\end{array}$ \\
\hline technologic & - & - & - & $>$ technological \\
\hline economical & $>$ economic & $>$ economic & $>$ economic & $\begin{array}{l}>\text { economic } \\
\text { economical }\end{array}$ \\
\hline lexicographic & - & - & - & $\begin{aligned}> & \text { lexicographic } \\
& \text { lexicographical }\end{aligned}$ \\
\hline academical & $\begin{array}{l}\text { > academicals } \\
\text { academically }\end{array}$ & $>$ academic & - & $>$ academic \\
\hline specifical & $>$ specifically & $>$ specific & $\begin{array}{l}\text { > specific } \\
\text { superficial } \\
\text { specifically } \\
\text { specifics } \\
\text { specificity }\end{array}$ & $\begin{array}{l}>\text { specific } \\
\text { specified }\end{array}$ \\
\hline electrical & - & $>$ electric & - & $\begin{array}{l}>\text { electric } \\
\quad \text { electrical }\end{array}$ \\
\hline electric & - & - & - & $\begin{array}{c}>\text { electricity } \\
\text { electrical } \\
\text { electric }\end{array}$ \\
\hline electrical & - & - & - & $\begin{array}{l}>\text { electric } \\
\quad \text { electrical }\end{array}$ \\
\hline electric & - & - & - & $\begin{array}{c}>\text { electrical } \\
\text { electric }\end{array}$ \\
\hline ironical & - & $>$ ironic & - & $\begin{array}{l}>\text { ironic } \\
\text { ironically }\end{array}$ \\
\hline
\end{tabular}

Table 12: Result from tests conducted with four writing assistants

The result is quite surprising. Grammarly and ProWritingAid have no objection to the relatively rare form scientifical whereas Microsoft's Spelling and Grammar Checker suggests the useless alternative scientifically. All three writing assistants suggest economic instead of the semantically wrong variant economical, but none of them catches the equally wrong variant classical (see Figure 9). Grammarly marks academical and electrical where the right collocations are academic writing and electric guitar, but it does not object to the less adequate collocation electric equipment (see Figure 11). The two other writing assistants mentioned do not even react to any of these funny collocations. Generally, the performance is disappointing although the three tools, especially Grammarly, provide at least some assistance to their users.

The test results from the other three writing assistants cannot be directly compared to the ones from Write Assistant. The former are conceived to work on the completed text whereas the latter is designed to predict word completions during the writing process as illustrated in Figura 13. Hence, Write Assistant always provides suggestions on how to complete the respective words. These suggestions get more and more precise for each letter typed by the writers. They are based on frequency and an analysis of the previous words, that is, they are the words most likely to be the next ones in a specific context (see Tarp et al. 2017 for a detailed description of Write Assistant's functionalities). 
When we consult some of the many web-based language fora, we may get recommendations for specifi

\begin{tabular}{l|} 
specific \\
specified \\
specifically \\
specification \\
specifics \\
specificity \\
specifications \\
specifies \\
specifiers \\
\hline
\end{tabular}

Figure 13: Screenshot from Write Assistant with suggested word completions

Table 12 above shows that Write Assistant comes up with the right alternative to all the wrong -ic/ical forms in the text. Due to its design, however, this software also suggests irrelevant alternatives although mostly not as first priority (see Figure 13). This design leaves it to the users to take responsibility and choose the final solution. If the users do not know which word to choose, they can access an integrated dictionary by clicking on the word. A new window will then pop up with explanations in their mother tongue as can be seen in Figure 14.

For instance, the existence of adverbs ending in -ically when only adjectives ending in -ic are used (e.g. domestic and $d c$ are not familiar with the English linguistic descriptions of these p] recommendations on how to writ overload that takes focus away fr the only information required is with the right meaning and wit or old-fashi

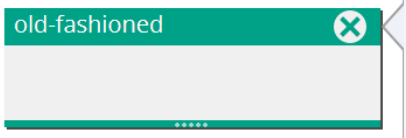

\section{old-fashioned}

\section{expression}

$\checkmark$ pasado de moda

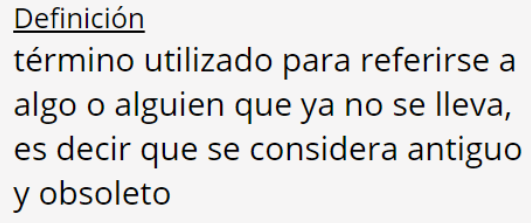

Figure 14: Screenshot from Write Assistant showing the consultation window

The other three writing assistants also include thesauruses (at least in their premium versions) but not with explanations in the non-native users' mother tongue. However, if these writing assistants do not call their users' attention to a possible problem, the users will probably not notice that they have a problem that requires a lexicographical consultation. In this respect, Write Assistant has the advantage that it continuously challenges its users and invites them to make consultations when they have some doubts.

These critical observations do not imply that other writing assistants do not have anything to contribute. On the contrary, their technology also appears to have a big future potential although it has not been fully integrated into the writing process like Write Assistant. For instance, Grammarly has already introduced the small standardized notes that we called for in the previous section when we analyzed a number of online dictionaries. 
economical $\rightarrow$ economic

The word economical doesn't seem to fit this

context. Consider replacing it with a different

one.

Figure 15: Screenshot from Grammarly with standardized note

Figure 15 shows such a standardized note that is used to address all alternative suggestions of a specific type, and where only one word (here: economical) has to be inserted each time. But in spite of these positive comments, we have to conclude that none of the existing writing assistants have yet cracked the -ic/-ical code. In the next section, we will therefore propose a solution that may lead to a better product.

\section{Proposal: treatment of -ic/-ical adjectives in writing assistants}

Digital writing assistants have the potential to completely revolutionize L2 writing. Fully developed, they will allow their users to speed up the writing process, improve the writing flow, avoid unnecessary distractions, focus on the message, and produce a better text. Today, writing is largely performed on digital devices whereas handwriting is increasingly restricted to the personal sphere. In this technological environment, writing assistants may little by little render traditional dictionaries superfluous as consultation tools in connection with L2 writing. A few well-designed writing assistants already allow their users to make lookups directly in integrated lexicographical databases. In addition, they have three big advantages compared to traditional online dictionaries:

1. They can detect problems that their users are not aware of.

2. They can respond instantaneously when a possible problem occurs.

3. They can provide assistance in the precise context where a problem is located (see Tarp/Gouws 2019).

However, as we saw in the previous section, writing assistants still have a long way to go before they are optimized in all three aspects. This also includes Write Assistant. The following proposal aims specifically at improving this tool (but can also be adapted to other writing assistants). The proposal is made from a lexicographical perspective and requires interdisciplinary collaboration to be implemented. As such, it focuses on the service provided in the consultation window and the capacity to call users' attention to problems they are not aware of. The point of departure is the three classes of -ic/-ical adjective pairs that require different lexicographical treatment (see Table 9). We will start with their selection and treatment in the lexicographical database and then continue to the presentation in Write Assistant. Finally, we will look at some special cases. But before doing so, we will briefly explain how the software works. 


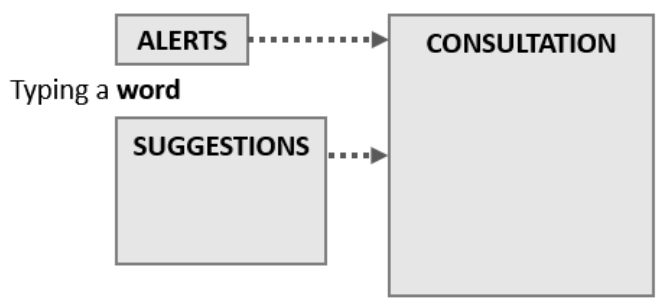

Figure 16: Schematic representation of Write Assistant's three data windows

Figure 16 is a schematic representation of the user interface. It works like this: A user types a text, e.g. in a Word document. A small window follows the typing and suggests L2 word completions, next-words, and equivalents (to L1 words typed by the user). The window provides three to ten suggestions depending on the user's preference. In case of doubts about any of the suggested words, a consultation window can be activated by a simple click as it was shown in the previous section (see Figure 14). The items presented in this window are imported from the lexicographical database where our proposal starts. However, a third window is also considered (see Tarp 2019). This window will give alerts to writers who may not be aware of a problem. It goes without saying that such alerts should not be given too frequently. Otherwise, they risk loosing their effect and may even become a disturbing element in the writing process. Alerts should be used carefully and only when absolutely necessary. The users should also have the option to deactivate them. But the very idea of issuing alerts fits perfectly with the second part of our proposal. As we stated above, it is not enough to look at Write Assistant and similar tools as they are currently designed. It is even more important to consider what they could develop into with the right input.

\subsection{Basic principles}

Before discussing the three classes of -ic/-ical adjective pairs, we will lay down three basic principles that concern the design of the lexicographical database and are relevant for all these pairs. The first one is that an -ic/-ical variant always should be stored in the database when its counterpart is selected, even if it falls below the frequency threshold established for the project in question. The reason for this rather unusual selection criterion is that non-native speakers sometimes, as we have seen, use an -ic or -ical form that native speakers seldom or never use, and that it is necessary to provide guidance in such cases.

The second general principle is that all-ic/-ical adjective forms, except for those that are not recommended, should be explained by means of an L1 definition. It is not enough to provide one or more equivalents as it is usually done in most bilingual dictionaries. Let us take a writer who does not know which L2 word to use and instead types the L1 word " $X$ " and gets its L2 equivalent "Y" in the suggestion window. Let us assume that the writer wants to make sure that "Y" has the right meaning and therefore activates the consultation window where he or she is informed that "Y" means " $X$ ". This tautology will probably confuse rather than help. Sometimes the two forms of an -ic/-ical adjective pair even share the same equivalent in the user's mother tongue. The Spanish adjective económico is a good illustration. It is the equivalent of both economic and economical, thus it cannot be used to distinguish between them.

Most existing lexicographical databases were designed without knowing the specific requirements of digital writing assistants. The need to furnish L1 definitions of L2 words implies that they suffer from structural deficiencies that make them less adequate to support a tool like Write Assistant. This represents a serious challenge to bilingual lexicography that has to reconsider some of its basic principles (see Fuertes-Olivera et al. 2018). 
The third general principle is that the meta-language, without any exception, should be the users' native language. This implies that not only the definitions, but also the usage notes, instructions, and standardized text segments which we discuss in the following should be written in this language.

\subsection{Three classes of adjective pairs - three different solutions}

Section 2 showed a few adjective pairs where the suffixes -ic and -ical express different meanings. The total number of such pairs is not big. But some of the adjective forms are among the most frequent words in English (see Table 1). It is therefore necessary to help learners and other non-native speakers to choose the right form. We propose the following solution: A small comparative usage note like the ones in Figures 8 and 9 is prepared. The meanings of the two forms are briefly explained. Additional instructions on how to use them are then provided. The instructions should include typical collocations, preferably shown in a relevant context (like in Figure 8). The usage notes are attached to both forms in the database (and can also be used in dictionaries). This includes all adjective pairs with the mentioned characteristics. Due to space constraints, only the comparative explanation of the two forms is presented as default in the consultation window (to avoid scrolling down). But it is clearly indicated how it can be expanded so the users can continue to the instructions, collocations, and examples sentences. In addition, for each pair the text segment, "X or Y?" is prepared. This text segment will then automatically pop up in the alert window every time the writer types one of the two forms of the adjective pair X-Y. The alert has two functions. It can function as a reminder for those users who already know the different meanings, but just forgot it for a moment because they were focusing on other aspects in the text. But it can also call the writers' attention to an unknown problem. In this last case, the writers can use the link to go directly to the comparative note in the consultation window.

Another class of lexicographically relevant-icl-ical adjective pairs is the one where the two forms have the same meaning and roughly similar frequency. As a rule, this class does not pose a problem or require special treatment in Write Assistant, unless the -ic/-ical forms tend to combine with specific nouns to form collocations and terms. In this respect, the current version of Write Assistant seems to have a structural problem. It always looks forward based on the previous words, but it does not know which word will come after the next word. It can therefore only guess which adjective form to use as it does not yet know the noun with which this form will combine. Other writing assistants that work with full texts have a clear advantage in this regard, although they still display some limitations as we saw in Table 11. The company behind Write Assistant has informed that a future version will be designed to also look back, i.e. to analyze and maybe suggest a different -ic/-ical form when the noun is known. The technology is already there. It only has to be applied and dressed in human-centered design, i.e. a design where one element does not disturb another one, and where users intuitively know what they get and how to use it (see Norman 2013).

There is no sharp dividing line between the first and second class of adjective pairs. Although they are here grouped as having the same meaning, they nevertheless show some minor and subtle semantic differences that may be difficult to grasp. This can be seen in the definitions of electric/ electrical provided in some of the five dictionaries consulted in Section 4 (where there also seems to be some differences between British and American English). Thus, their lexicographical treatment has to be individualized and adapted to each pair. As a solution to Write Assistant, we propose that small usage notes are elaborated and attached to both forms, not only to one of them. These notes should contain default data on possible semantic nuances and the usage with specific groups of nouns as it is done in Figure 11. They should include a list of frequent and wellestablished collocations and terms like the ones with electric and electrical in Table 10. The usage notes should be addressed to the respective -ic/-ical forms in the database and made accessible under these forms in the consultation window. Access should also be provided directly from the 
alert window where the text segment "X or Y?" should pop up every time one of the two forms are typed by the writer.

The third class of adjective pairs to be treated here is the one where a possible problem is related to very different frequencies. To solve this problem, we propose that the following three standardized notes are prepared:

1. "X is not used. Use Y instead!"

2. "X is rarely used. Use $\mathrm{Y}$ instead!"

3. "X is old-fashioned. Use $\mathrm{Y}$ instead!"

These notes are only attached to the non-recommended -ic/-ical forms $(\mathrm{X})$ in the database, from where there is a link to the recommended form (Y). They can also be used as alerts that are only activated when the users type non-recommended -ic/-ical forms. That is, the notes are never shown in relation to the recommended forms, neither in the consultation nor in the alert window. They are only shown in relation to the non-recommended ones. This way of treating -ic/-ical forms with very different frequencies has three advantages. First, writers are explicitly recommended to use a specific form. Second, they are briefly informed about why they are referred to this form. And third, the standardized notes are very easy to handle for the lexicographers.

\subsection{Special challenges}

The -ic/-ical pairs are not limited to adjectives. They also include several noun-adjective pairs where one of the forms, mainly the -ic form, has a nominal function. As we saw in Section 3, the dominant tendency is that the -ical form is preferred over the -ic form as an adjective, but there are other possible combinations of nominal and adjectival functions. All these combinations require usage notes that are specifically adapted to each noun-adjective pair and can be accessed in the consultation window. However, they do not necessarily call for alerts as the latter, in some instances, may be more confusing than helpful. In any case, this is a field that requires further research. The following recommendations on the use of alerts should therefore be regarded as preliminary:

1. The -ical form is preferred over the -ic form as an adjective: an alert should be provided, but only when the writer types the $-i c$ form.

2. The adjectival function is not exclusively reserved for the -ical form: no alerts should be issued.

3. The -ic form prevails, although this form also has a nominal function: an alert should be given, but only when the writer types the -ical form.

4. The longer -ical form, rather than the shorter -ic form, denotes a noun: an alert should be given, but only when the writer types the $-i c$ form.

\subsection{Additional remarks}

The current version of Write Assistant is only conceived to assist users that need assistance when writing in a non-native language. However, the company behind the software informs that a pedagogical function is also considered in the future. Our proposal focuses on the writing assistance. But we believe that it also contributes to the projected pedagogical function. The definitions and usage notes written in the users' native language, as well as the combination of suggestions, consultation options, and alerts, herald a product that can be used to both incidental and intentional language learning. 


\section{Perspectives}

We are not up against the Aristotelian or any other cosmology. Neither are we pretending to make contributions as groundbreaking as the ones that immortalized Galileo's name. But we are inspired by his example. Like the Italian scientist, we have taken an old question and looked upon it from a new angle, through the prism of recent technological breakthroughs.

The correct use of the suffixes -ic and -ical in connection with a big number of adjectives is a longtime challenge to non-native learners of English. Even those who have reached a high proficiency level and aspire to write academically in the language of Shakespeare may occasionally struggle with these suffixes. The choice between the two variants is tricky due to the lack of general rules that can be applied. Until now, dictionaries have been about the only crutches offered to those who feel limb. As we have seen, some of them have picked up the gauntlet. But they are far from perfect. Recently, writing assistants based on disruptive technologies have started offering additional assistance, at least in some cases and to some extent. However, the assistance seems to be a technological byproduct rather than the result of a conscious and focused study of the problem. They could perform much better.

In the previous section, we have approached the question from a new angle and outlined a proposal for a multidimensional treatment of -ic/-ical adjectives in integrated writing assistants. The proposal has several advantages, among them:

- It provides assistance when writers are both aware and unaware of a problem.

- It serves learners both at a low and a high proficiency level.

- It allows for both incidental and intentional L2 learning.

- It combines the writers' active participation with automatically generated suggestions and alerts.

- It can be adapted to different types of writing assistant.

The vision is to make full use of current technologies by means of interdisciplinary collaboration that combines knowledge from different fields such as natural language processing, secondlanguage learning, lexicology, lexicography, and human-centered design. The collaboration must be genuine and not just business as usual with everybody contributing what they already have. The objective is to "synthesize new things" by connecting dots and avoid ending up "with very linear solutions without a broad perspective on the problem", as Steve Jobs once pointed out (Wolf 1996). This implies, among other things, that each discipline must look into its own backyard and spot what could be done differently to serve the overall purpose. Lexicography, for instance, needs to design databases with completely new data categories like alerts and their corresponding explanations, descriptions, and recommendations.

The -icl-ical adjectives discussed in this article may be regarded as a peripheral problem. But there are other grammatical problems that could benefit from a similar up-to-date treatment, both in English and other languages. Recent technological breakthroughs require that old questions are viewed with fresh eyes. New solutions have become possible. As in Galileo's case, it all boils down to intellectual courage, foresight, and creativity. Join the party or stop grumbling. Eppur si muove.

\section{Acknowledgments}

Special thanks are due to the Center for Lexicographical Studies at Guangdong University of Foreign Studies, China, for appointing Sven Tarp as Yunshan Chair Professor (2019-2021), thus making the collaboration between the two authors of this article possible. 


\section{References}

\section{A. Dictionaries}

Collins English Dictionary. [online]. https://www.collinsdictionary.com/ (accessed 26 January 2020)

Longman Dictionary of Contemporary English Online. [online]. https://www.ldoceonline.com/ (accessed 26 January 2020)

Macmillan Dictionary. [online] http://www.macmillandictionaries.com/ (accessed 26 January 2020)

Merriam-Webster Dictionary. [online] https://www.merriam-webster.com/ (accessed 26 January 2020)

Oxford Advanced Learner's Dictionary. [online]. https://www.oxfordlearnersdictionaries.com/ (accessed 26 January 2020)

\section{B. Writing assistants}

Academic Writing Assistant. [online]. https://awa.schrijfhulp.be/. (accessed 26 January 2020)

Ginger. [online]. https://www.gingersoftware.com/. (accessed 26 January 2020)

Grammarly. [online]. https://www.grammarly.com/. (accessed 26 January 2020)

ProWritingAid. [online]. https://prowritingaid.com/. (accessed 26 January 2020)

WhiteSmoke. [online]. https://www.whitesmoke.com/. (accessed 26 January 2020)

Write Assistant. [online]. https://writeassistant.com/en/. (accessed 26 January 2020)

Writefull. [online]. https://writefullapp.com/. (accessed 26 January 2020)

\section{Other literature}

Aronoff, Mark/Lindsay, Mark 2014: Productivity, Blocking, and Lexicalization. In Lieber, Rochelle/ Štekauer, Pavol (eds.), The Oxford Handbook of Derivational Morphology. Oxford: Oxford University Press, 67-83.

Bergenholtz, Henning 2003: User-oriented Understanding of Descriptive, Proscriptive and Prescriptive Lexicography. In Lexikos 13, 65-80.

Bergenholtz, Henning/Bergenholtz, Inger 2011: A dictionary is a Tool, a Good Dictionary is a Monofunctional Tool. In Fuertes-Olivera, Pedro A./Bergenholtz/Henning (eds.), e-Lexicography: The Internet, Digital Initiatives and Lexicography. London, New York: Continuum, 187-207.

Bothma, Theo J.D./Tarp, Sven 2012: Lexicography and the Relevance Criterion. In Lexikos 22, 86-108.

Cabral, José Jesús Alvarado/Soto, Olga Soto/ Lares, Juan José Rodríguez Lares 2018: Didactic Strategies to Improve the Competencies in Analytical Reading and Academical Writing of Future Teachers and Teachers in Service. In European Journal of Multidisciplinary Studies 3(3), 155-166.

Einstein, Albert/Infeld, Leopold 1938: The Evolution of Physics. New York: Simon \& Schuster.

Fletcher, William H. (ed.) 2011: Phrases in English. [online]. http://phrasesinenglish.org/index.html\#. (accessed 26 January 2020).

Frankenberg-García, Ana 2020: Combining User Needs, Lexicographic Data and Digital Writing Environments. In Language Teaching 53(1), 1-16.

Frankenberg-García, Ana/Lew, Robert/Roberts, Jonathen C./Rees, Geraint Paul/Sharma, Nirvan 2019: Developing a Writing Assistant to Help EAP Writers with Collocations in Real Time. In ReCALL 31(1), $23-39$.

Fuertes-Olivera, Pedro A. 2016: A Cambrian Explosion in Lexicography: Some Reflections for Designing and Constructing Specialised Online Dictionaries. In International Journal of Lexicography 29(2), $226-247$.

Fuertes-Olivera, Pedro A. 2019: Designing and Making Commercially Driven Integrated Dictionary Portals: the Diccionarios Valladolid-Uva. In Lexicography 6(1), 21-41.

Fuertes-Olivera, Pedro A./Tarp, Sven 2014: Theory and Practice of Specialised Online Dictionaries: Lexicography versus Terminography. Berlin, Boston: De Gruyter.

Fuertes-Olivera, Pedro A./Tarp, Sven/Sepstrup, Peter 2018: New Insights in the Design and Compilation of Digital Bilingual Lexicographical Products: the Case of the Diccionarios Valladolid-UVa. In Lexikos 28, $152-176$.

Gouws, Rufus H./Tarp, Sven 2017: Information Overload and Data Overload in Lexicography. In International Journal of Lexicography 30.4, 389-415.

Granger, Sylviana/Paquot, Magali 2015: Electronic Lexicography Goes Local: Design and Structures of a Needsdriven Online Academic Writing Aid. In Lexicographica 31.1, 118-141. 
Gries, Stefan Th. 2001: A Corpus-linguistic Analysis of English -ic vs -ical Adjectives. In ICAME Journal 25, 65-108.

Gries, Stefan Th. 2003: Testing the Sub-test: An Analysis of English -ic and -ical Adjectives. In International Journal of Corpus Linguistics 8(1), 31-61.

Kaunisto, Mark 1999: Electric/Electrical and Classic/Classical: Variation between the Suffixes -ic and -ical. In English Studies 80(4), 343-370.

Kaunisto, Mark 2007: Variation and Change in the Lexicon: A Corpus-based Analysis of Adjectives in English Ending in -ic and-ical. New York: Rodopi.

Lew, Robert/Frankenberg-Garcia, Ana/Rees, Geraint Paul/Roberts, Jonathan C./Sharma, Nirvan 2018: ColloCaid: A Real-time Tool to Help Academic Writers with English Collocations. Proceedings of the XVIII EURALEX International Congress. Ljubljana: Ljubliana University Press, Faculty of Arts, 247-254.

Li, Chong-yue 2002: A Study of Differences between Adjective Suffixes -ic and -ical and their Relevant Aspects. In Journal of Jiangsu University (Higher Education Study Edition) 24(4), 58-60.

Lindsay, Mark/Aronoff, Mark 2013: Natural Selection in Self-organizing Morphological Systems. In Hathout, Nabil/ Montermini, Fabio/Tseng, Jesse (eds.), Morphology in Toulouse: Selected Proceedings of Décembrettes 7. München: LINCOLM Europa, 133-153.

Longman Communication 3000. [online]. https://www.lextutor.ca/freq/lists_download/longman_3000_list.pdf. (accessed 26 January 2020).

Marchand, Hans 1969: The Categories and Types of Present-day English Word Formation. A Synchronic-diachronic Approach. München: C.H. Beck'sche Verlagsbuchhandlung.

Manser, Martin H. (ed.) 2003: Bloomsbury Good Word Guide. London: Bloomsbury.

Norman, Don 2013. The Design of Everyday Things. New York: Basic Books.

Paquot, Magali 2012: The LEAD Dictionary-cum-writing Aid: an Integrated Dictionary and Corpus Tool. In Granger, Sylviana/Paquot, Magali (eds.), Electronic lexicography. Oxford: Oxford University Press, 163-185.

Patridge, Eric 1957: Introduction to Theoretical Linguistics. London: Cambridge University Press.

Quirk, Randolph/Greenbaum, Sidney/Leech, Geoffrey/Svartvik 1985: A Comprehensive Grammar of the English Language. London: Longman.

Ross, Nigel J. 1998: The -ic and -ical Pickle. In English Today 14(2), 40-44.

Rundell, Michael 2014: Macmillan English Dictionary: The End of Print? Slovenščina 2.0 2.2, 1-14.

Scerba, Lev V. 1995: Towards a General Theory of Lexicography. In International Journal of Lexicography 8(4), 315350 .

Schwab, Karl 2015: The Fourth Industrial Revolution: What It Means and How to Respond. In Foreign Affairs. $12^{\text {th }}$ December, 2015. [online]. www.foreignaffairs.com/articles/2015-12-12/fourth-industrial-revolution. (accessed 26 January 2020).

Simonsen, Henrik Kølner 2017: Lexicography: What is the Business Model? In Kosem, Iztok/Kallas, Jelena/Tiberius, Carole/Jakubiček, Milo/Kallas, Jelena/Krek, Simon/Baisa, Vit (eds.), Electronic Lexicography in the $21^{\text {st }}$ Century. Proceedings of the eLex 2017 Conference, 2017. Brno: Lexical Computing CZ, 395415. [online]. elex.link/elex2017/ proceedings-download/. (accessed 26 January 2020).

Sweet, Henry 1899: The Practical Study of Languages: A Guide for Teachers and Learners. London: Oxford University Press.

Tarp, Sven 2008: Lexicography in the Borderland between Knowledge and Non-knowledge. General Lexicographical Theory with Special Focus on Learner's Lexicography. Tübingen: Niemeyer.

Tarp, Sven 2014: Theory-Based Lexicographical Methods in a Functional Perspective: An Overview. In Lexicographica 30, $58-76$

Tarp, Sven 2019: Connecting the Dots: Tradition and Disruption in Lexicography. In Lexikos 29, 224-249.

Tarp, Sven 2020: Integrated Writing Assistants and their Possible Consequences for Foreign-Language Writing and Learning. In Bocanegra-Valle, Ana (ed.), Applied Linguistics and Knowledge Transfer: Employability, Internationalization and Social Challenges. Bern: Peter Lang, 45-64.

Tarp, Sven/Fisker, Kasper/Sepstrup, Peter 2017: L2 Write Assistants and Context-aware Dictionaries: New Challenges to Lexicography. In Lexikos 27, 494-521.

Tarp, Sven/Gouws, Rufus H. 2019: Lexicographical Contextualization and Personalization: a New Perspective. In Lexikos 29, 250-268.

Verlinde, Serge 2011: Modelling Interactive Reading, Translation and Writing Assistants. In Fuertes-Olivera, Pedro A./Bergenholtz, Henning (eds.), e-Lexicography: The Internet, Digital Initiatives and Lexicography. London, New York: Continuum, 275-286. 
Viviani, Vincenzo 1717: Racconto istorico della vita di Galileo Galilei. Firenze: Nella Stamperia S.A.R. Per Gio: Gaetano, e Sant Franchi.

Wanner, Leo/Verlinde, Serge/Alonso-Ramos, Margarita 2013: Writing Assistants and Automatic Lexical Error Correction: Word Combinatorics. In Kosem, Iztok/Kallas, Jelena/Gantar, Polona/Krek, Simon/Langemets, Margit/ Tuulik, Maria (eds.), Electronic Lexicography in the 21st Century: Thinking Outside the Paper. Ljubljana: Institute for Applied Slovene Studies, 472-487.

Winestock, Christopher/Jeong, Young-kuk 2014: An Analysis of the Smartphone Dictionary App Market. In Lexicography 1(1), 109-119.

Wolf, Gary 1996: Steve Jobs: The Next Insanely Great Thing. In Wired, 1st February, 1996. [online]. https://www. wired.com/1996/02/jobs-2/ (accessed 26 January 2020).

Xu, Hong-liang 2010: A Preliminary Study of Adjectives Ending in -ic and -ical. In Journal of Fuyang Teachers College (Social Science) 136(4), 36-38.

Zhang, Rong-jian 1999: The Choice between the English Suffixes -ic and -ical. In The Knowledge of English 143.12, 32-33. 